\title{
Cancer treatment-related neuropathic pain: proof of concept study with menthol—a TRPM8 agonist
}

\author{
M. T. Fallon • D. J. Storey • A. Krishan • C. J. Weir • R. Mitchell • \\ S. M. Fleetwood-Walker • A. C. Scott • L. A. Colvin
}

Received: 12 January 2015 / Accepted: 28 January 2015 / Published online: 15 February 2015

(C) The Author(s) 2015. This article is published with open access at Springerlink.com

\begin{abstract}
Purpose Effective treatment of neuropathic pain without unacceptable side effects is challenging. Cancer sufferers increasingly live with long-term treatment-related neuropathic pain, resulting from chemotherapy-induced peripheral neuropathy (CIPN) or surgical scars. This proof-of-concept study aimed to determine whether preclinical evidence for TRPM8 ion channels in sensory neurons as a novel analgesic target could be translated to clinical benefit in patients with neuropathic pain, using the TRPM8 activator menthol.

Patients and methods Patients with problematic treatmentrelated neuropathic pain underwent a baseline assessment using validated questionnaires, psychophysical testing, and objective functional measures. The painful area was treated with topical $1 \%$ menthol cream twice daily. Assessments were repeated at 4-6 weeks. The primary outcome was the
\end{abstract}

Where presented in part elsewhere: Chemotherapy induced neuropathy subgroup presented at ASCO 2011

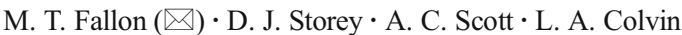

Edinburgh Cancer Research Centre (IGMM),

University of Edinburgh, Edinburgh EH4 2XR, UK

e-mail: Marie.Fallon@ed.ac.uk

A. Krishan

Edinburgh Clinical Trials Unit, University of Edinburgh,

Edinburgh, UK

C. J. Weir

MRC Hub for Trials Methodology Research, Centre for Population

Health Sciences, University of Edinburgh, Edinburgh, UK

R. Mitchell

Centre for Integrated Physiology, University of Edinburgh,

Edinburgh, UK

S. M. Fleetwood-Walker

Centre for Neuroregeneration, University of Edinburgh,

Edinburgh, UK change in Brief Pain Inventory total scores at 4-6 weeks. Secondary outcomes included changes in function, mood and skin sensation.

Results Fifty-one patients (female/male, 32/19) were recruited with a median age of 61 (ranging from 20 to 89). The commonest aetiology was CIPN (35/51), followed by scar pain (10/51). Thirty-eight were evaluable on the primary outcome. Eighty-two per cent (31/38) had an improvement in total Brief Pain Inventory scores (median, 47 (interquartile range, 30 to 64 ) to 34 (6 to 59), $P<0.001$ ). Improvements in $\operatorname{mood}(P=0.0004)$, catastrophising $(P=0.001)$, walking ability $(P=0.008)$ and sensation $(P<0.01)$ were also observed.

Conclusion This proof-of-concept study indicates that topical menthol has potential as a novel analgesic therapy for cancer treatment-related neuropathic pain. Improvements in patientrated measures are supported by changes in objective measures of physical function and sensation. Further systematic evaluation of efficacy is required.

Keywords Menthol · TRPM8 · Neuropathic $\cdot$ Pain · Cancer $\cdot$ Chemotherapy

\section{Introduction}

Chronic neuropathic pain, resulting from nerve injury, is a challenging clinical problem which is difficult to treat with current analgesics without unacceptable side effects. It greatly reduces quality of life, even more so than other chronic pain states with a negative impact on mobility, function, mood and general wellbeing [1]. The prevalence of neuropathic pain is likely to be underestimated, but studies from North America and Europe have found between 8 and $17 \%$ of the population may suffer from pain of predominantly neuropathic origin [2-4]. Neuropathic pain associated with cancer treatment is an increasing challenge. As the incidence of cancer increases 
and survival improves with better oncological management, there is an increasing number of patients living with the longterm effects of treatment such as chemotherapy-induced peripheral neuropathy (CIPN) or surgical scar pain $[5,6]$.

CIPN affects up to $96 \%$ of patients who receive potentially neurotoxic chemotherapy (e.g. platinums, taxanes, vincaalkaloids and bortezomib), resulting in dose reduction or early cessation of treatment for up to $50 \%$ [7-10]. Symptoms are commonly in a glove and stocking distribution and include spontaneous pain, paraesthesia, allodynia (nonpainful stimuli causing pain), hyperalgesia (increased sensitivity to painful stimuli), hypoaesthesia (numbness) and impaired proprioception, causing difficulty with day-to-day functioning such as fastening buttons, handling coins, walking and driving. In our centre, $50 \%$ of colorectal cancer patients still had symptoms of neuropathy 12 months after completing treatment with curative intent [5].

Estimates for persistent neuropathic pain after cancer surgery vary, with post-mastectomy and post-thoracotomy pain occurring in 30-60\% of patients [11]. One large study after breast cancer surgery found almost half of patients had persistent pain 2 to 3 years later, with this being moderate to severe in nearly a quarter of patients [12]. In our own centre, approximately $30 \%$ of patients had persistent post-mastectomy pain, with a threefold increase in risk conferred by adjuvant chemotherapy [13]. Recent guidelines suggest the use of objective quantifiable tests such as Quantitative Sensory Testing as clinical biomarkers to strengthen the diagnosis of neuropathic pain, which is made on history and examination $[14,15]$.

Treatment of neuropathic pain relies on early identification, understanding of the initiating and sustaining pathophysiological mechanisms and use of a range of therapeutic approaches [16]. Evidence is accumulating which suggests that the neurosensory characteristics of the pain may be the most important factor in predicting a treatment response, rather than the underlying aetiology $[17,18]$. Current systemic therapy is mainly oral antidepressants or anticonvulsants; however, treatment often requires titration over months and is limited by variable efficacy and unacceptable side effects [19]. Nontoxic therapies, which reduce pain with minimal side effects, are needed.

A new potential novel therapeutic approach has arisen as a result of basic science findings from our translational research group which demonstrated that endogenous neural circuitry underlying cooling-induced analgesia may represent a novel target for intervention. Molecular receptors for cooling have been identified in sensory nerves with evidence for their upregulation in neuropathic pain models [20,21]. Our group identified how activation of one of these, the transient receptor potential melastatin (TRPM) 8 ion channel, by topical agents, produced significant analgesia [22]. As a result of this work, we successfully used topical menthol, a TRPM8 agonist, in two cases of treatment-resistant chemotherapy-induced peripheral neuropathy, allowing continuation of lifeprolonging treatment $[23,24]$. If topical TRPM8 agonists produced profound, mechanistically novel analgesia in chronic neuropathic pain, this would be a significant advance.

\section{Aims}

The primary aim of this study is to determine whether 46 weeks of topical $1 \%$ menthol in aqueous cream provided effective analgesia for neuropathic pain in a proof-of-concept study (assessed using the Brief Pain Inventory).

The secondary aims of this study is to determine whether mood and surrogate clinical measures (biomarkers) of neuropathic pain (physical function and quantitative sensory testing) improved after 4-6 weeks of topical $1 \%$ menthol in aqueous cream.

\section{Methods}

This was an open-label proof-of-concept study. After obtaining research ethics committee approval and written informed consent, suitable patients were recruited from the Edinburgh Regional Cancer Centre. For inclusion, patients had to meet the following criteria: chronic neuropathic pain (diagnosed by a palliative medicine or pain medicine specialist); stable pain, not expected to change within the following 6 weeks; an average pain severity of $\geq / 4$ on a 0 to 10 scale; aged 18 years or over; and either had tried conventional antineuropathic agents or these were contraindicated/declined. Patients were excluded if they had any medical or psychiatric condition that would confound the study objectives. Patients underwent a comprehensive assessment of pain and its impact on function immediately prior to treatment and after 2 and 4 6 weeks of treatment, as recommended by the Initiative on Methods, Measurement and Pain Assessment in Clinical Trials (IMMPACT) [25]. Standard demographic data were collected. The $1 \%(-)$ menthol (levomenthol) in aqueous cream was used topically. Each patient was instructed on how to apply the cream to the affected area and corresponding dermatomal region of spine, twice daily on a regular basis.

Each assessment comprised:

1. Validated self-report questionnaires to assess the sensory, cognitive and affective components of pain, with higher scores representing more severe symptoms:

a. The short-form Brief Pain Inventory (BPI): an 11item assessment using a 0 (no pain/interference) to 10 (worst pain/interference) rating scale of pain intensity and its impact (interference with general activity, mood, walking ability, normal work, relations with 
others, sleep and enjoyment of life over the last week). The total BPI is the sum of all 11 items (ranging from 0 to 110), the interference subscale is the total of the seven interference items (ranging from 0 to 70) [26].

b. Hospital Anxiety and Depression scale (HADS): with a range of 0-21 for both anxiety and depression [27].

c. Pain Catastrophising scale: This measures rumination, magnification and helplessness. Range of 0-65, with values of $>30$ thought to be of clinical significance [28].

d. Leeds Assessment of Neuropathic Symptoms and Signs (LANSS): is a validated screening tool for neuropathic pain (range $0-24$, score $\geq 12$ is indicative of neuropathic pain) [29].

2. Surrogate clinical biomarker measures of neuropathic pain:

a. Objective measures of functional performance:

i. Walking ability was assessed using a GAITRite ${ }^{\circledR}$ walking mat to measure gait velocity $(\mathrm{cm} / \mathrm{s})$ and cadence (steps/min) [30].

ii. Hand dexterity. Patients were instructed to fill a fiveby-five slotted board with grooved pegs in an ordered fashion. The time taken (s) to do this with the dominant and nondominant hands was recorded [31, 32].

b. Quantitative Sensory Testing (QST) was conducted using our well-established protocol that has been used successfully in frail patients [33]. Skin overlying the affected area and an unaffected control area were assessed (either the equivalent contralateral dermatomal region, or for patients with bilateral peripheral neuropathy, a more proximal unaffected area). Testing was carried out in a quiet environment with the patient relaxed and took 20-40 min. All researchers underwent standardised QST training to use the following protocol:

i. The affected area was mapped using a calibrated brush (Senselab 0.5 mN Somedic, Sweden) moving from normal to affected areas. Areas of abnormal sensation were marked out on the skin. The patient was asked to describe how this sensation compared with the control area (hyperaesthesia, hypoaesthesia or unchanged) and, if painful, it was rated on a 0 to 10 numerical rating scale (NRS). The area of abnormal sensation was measured using tracing paper (recorded in $\mathrm{cm}^{2}$ for patients with scar pain) or distance $(\mathrm{cm})$ measured from the middle finger tip or great toe for peripheral neuropathies. For the latter, the percentage of the limb affected was calculated as a proportion of the distance from the finger tip/great toe to the olecranon/inferior patella border. ii. Thermal sensory mapping was conducted in a similar way using warm $\left(40^{\circ} \mathrm{C}\right)$ and $\operatorname{cool}\left(25^{\circ} \mathrm{C}\right)$ rollers (Rolltemp, Somedic, Sweden).

iii. Mechanical Detection Threshold (MDT) and Mechanical Pain Threshold (MPT) were assessed with 17 von Frey monofilaments of varying thickness, calibrated according to the force required to make them bend ( 0.026 to $110 \mathrm{~g}$, Somedic, Sweden). Using the Method of Levels the monofilaments were applied to the skin in ascending order and the MDT noted when felt consistently (detecting three out of five applications). MPT was the force when the stimulus became unpleasant and rated using a NRS from 0 to 10 .

iv. Mechanical pain sensitivity (hyperalgesia) was tested using noxious pin prick stimulus (Neurotips ${ }^{\mathrm{TM}}$ Owen Mumford) and rated using an NRS from 0 to 10 .

v. Temporal summation was assessed using five rapidly repeated pin prick stimuli and a NRS rating. The wind up ratio was calculated as the NRS score (repeated stimuli)/NRS score (single stimulus) [34].

Table 1 Patients' characteristics at baseline

\begin{tabular}{ll}
\hline Neuropathic pain aetiology & Total $n=51(n(\%))$ \\
\hline CIPN & $31(61)$ \\
Chemotherapy & \\
Oxaliplatin & $21(41)$ \\
$\quad$ Paclitaxel & $2(4)$ \\
Taxotere & $1(2)$ \\
Bortezomib & $2(4)$ \\
Cisplatin & $4(8)$ \\
Carboplatin & $1(2)$ \\
Median months since last dose (IQ range) & $11(8$ to 24$)$ \\
Neuropathic scar pain & $10(20)$ \\
Neuropathic pain due to other causes & $10(20)$ \\
Median months of pain: all causes (IQ range) & $19(9$ to 34$)$ \\
Previous/current cancer diagnosis & $41(80)$ \\
Type of cancer & \\
Colorectal & $22(43)$ \\
Multiple myeloma & $2(4)$ \\
Lung & $3(6)$ \\
Ovary & $2(4)$ \\
Breast & $12(23)$ \\
Cancer status & \\
No recurrence & $33(65)$ \\
Local disease & $6(12)$ \\
Metastatic disease & $2(4)$ \\
\hline &
\end{tabular}

$I Q$ interquartile, $C I P N$ chemotherapy-induced peripheral neuropathy 
Statistical analysis

Data were displayed as mean (standard deviation (SD)), median (interquartile range) or proportions as appropriate. Continuous variables at baseline and 4-6 weeks were compared using the Wilcoxon signed rank test or paired $t$ test as appropriate. The primary variable of interest was the change in pain as assessed by the total BPI. Responders were defined as a $\geq 30 \%$ reduction in total $\mathrm{BPI}$, which is considered to be a clinically meaningful improvement [35]. Responders and nonresponders were compared, to define any patient characteristics associated with a treatment response, using the Mann-Whitney $U$ test or two-sample $t$ test as appropriate. This was an exploratory analysis and a $P$ value of $<0.05$ was considered statistically significant with no correction for multiple testing.

\section{Results}

Fifty-one patients entered the study. The median age was 61 (ranging from 20 to 89$)$, and the majority were female (32/51, $63 \%)$. Most had been treated for cancer $(41 / 51,80 \%)$ and the majority of these were recurrence free $(33 / 41,80 \%)$. The commonest neuropathic pain aetiology was CIPN (31/51, $61 \%$ ), followed by scar pain $(10 / 51,20 \%$, most frequently post-mastectomy) and miscellaneous reasons (10/51, $20 \%$ ) (Table 1). Thirty (59\%) patients had tried a range of standard analgesics and anti-neuropathic agents. During the study period $7(14 \%)$, patients were on a variety of standard analgesics, with no relevant medication change during the study period. Forty-four (86\%) patients were on no analgesics during the study period.

Forty of fifty-one patients completed 4-6 weeks of treatment. Ten patients discontinued the topical menthol treatment early for the following reasons: disliked the cream $(n=2)$, found cream application difficult $(n=2)$, developed brain metastases $(n=1)$, felt no benefit $(n=1)$, pain worsened $(n=2)$, (resolved to baseline levels within 2 weeks of stopping menthol) or withdrew from the trial without giving a reason $(n=2)$. One patient only attended at 10 weeks after baseline, so did not complete the 4-6-week assessment. Thirty-eight patients had complete evaluable outcome data. All completing patients used very similar quantities of menthol cream over the study period $(1000 \times g$, i.e. $10 \mathrm{~g}$ menthol $)$.

Change in pain scores and other patient-rated outcomes

Eighty-two per cent (31/38) of evaluable patients had an improvement in their pain scores. The median total BPI improved from 47 (interquartile range, 30 to 64 ) to 34 (6 to

Table 2 Comparison of measures at baseline and after 4-6 weeks of menthol

\begin{tabular}{|c|c|c|c|c|c|}
\hline $\begin{array}{l}\text { Measure } \\
\text { (possible score) }\end{array}$ & Number & $\begin{array}{l}\text { Baseline median } \\
\text { (IQ range) }\end{array}$ & $\begin{array}{l}4-6 \text { weeks median } \\
\text { (IQ range) }\end{array}$ & $\begin{array}{l}\text { Mean/median of individual } \\
\text { changes }^{\mathrm{b}}(95 \% \mathrm{CI})\end{array}$ & $P$ value \\
\hline \multicolumn{6}{|l|}{ Brief Pain Inventory ${ }^{\mathrm{a}}$} \\
\hline Total BPI (0 to 110$)$ & 38 & 47 (30 to 64$)$ & $34(6$ to 59$)$ & $-11(-16.1$ to -5.5$)$ & $<0.001$ \\
\hline Worst pain item (0 to 10$)$ & 39 & $6(4$ to 7$)$ & $3(1$ to 7$)$ & $-1.3(-2.1$ to -0.6$)$ & 0.001 \\
\hline Total interference (0 to 70$)$ & 38 & $32(17$ to 43$)$ & 24 (3 to 37$)$ & $-6.3(-10.2$ to -2.5$)$ & 0.002 \\
\hline \multicolumn{6}{|l|}{$\mathrm{HADS}^{\mathrm{a}}$} \\
\hline Depression (0 to 21) & 38 & $4(2$ to 7$)$ & $4(1$ to 6$)$ & $0^{\mathrm{b}}(-1.6$ to 0.1$)$ & $0.168^{\mathrm{c}}$ \\
\hline Anxiety ( 0 to 21$)$ & 38 & 7.5 (4 to 9$)$ & $5(2$ to 8$)$ & $-1.7(-2.6$ to -0.8$)$ & 0.001 \\
\hline Total (0 to 42$)$ & 38 & $12(6$ to 16$)$ & $9(5$ to 13$)$ & $-2.5(-4.1$ to -0.8$)$ & 0.004 \\
\hline $\mathrm{PCS}^{\mathrm{a}}(0$ to 65$)$ & 37 & 13 (9 to 19$)$ & $10(2$ to 17$)$ & $-4.5(-7.0$ to 2.0$)$ & 0.001 \\
\hline $\operatorname{LANSS}^{\text {a }}$ (0 to 24$)$ & 40 & 14 (11 to 19$)$ & $13(8$ to 19$)$ & $-1.1(-2.6$ to 0.4$)$ & 0.160 \\
\hline \multicolumn{6}{|l|}{ Peg board ${ }^{\mathrm{a}}$} \\
\hline Dominant hand (s) & 15 & 98 (79 to 147$)$ & $85(77$ to 103$)$ & $-10.8(-34$ to 12.5$)$ & 0.337 \\
\hline Nondominant hand (s) & 15 & 95 (92 to 147$)$ & $92(76$ to 102$)$ & $-13.5(-34.7$ to 7.7$)$ & 0.195 \\
\hline \multicolumn{6}{|l|}{ GAITRite } \\
\hline Velocity (metres/s) & 21 & 79 (68 to 106$)$ & 93 (79 to 113$)$ & 12.1 (3.6 to 20.6$)$ & 0.008 \\
\hline Cadence (steps/min) & 21 & $100(89$ to 110$)$ & 105 (96 to 113$)$ & $6.0(0.8$ to 11.2$)$ & 0.027 \\
\hline
\end{tabular}

BPI Brief Pain Inventory, HADS Hospital Anxiety and Depression scale, LANSS Leeds Assessment of Neuropathic Symptoms and Signs, PCS Pain Catastrophising scale $95 \%$ CI $95 \%$ confidence interval, IQ range interquartile range

${ }^{\text {a }}$ Higher scores indicate more severe symptoms

${ }^{\mathrm{b}}$ Median change (when distribution of variables relating to the change between baseline and 4-6 weeks was not normally distributed)

${ }^{\mathrm{c}}$ Exception—compared using paired $t$ test when Wilcoxon signed rank test used 
59), $P<0.001$. There were also significant improvements in 'worst pain' and the pain interference subscales (Table 2). The mean total BPI decrease was 11 (SD 16). Fifty per cent (19/38) were responders, with $11 \%(4 / 38)$ having complete pain relief. All the statistically significant improvements in pain were also clinically significant [21]. Along with the improvement in pain scores, there were also statistically significant improvements in HADS total score, HADS anxiety score and catastrophising (Table 2). The LANSS scores, as expected, did not demonstrate any significant treatment effect. Patients who were taking other regular pain medication remained on the same dose throughout the 6 weeks.

Change in quantitative sensory testing (QST), objectively measured walking ability and hand dexterity

As well as an improvement in subjectively rated pain, there was also an improvement in objectively measured physical function and some QST parameters. Both walking velocity and cadence improved over the treatment period, although there was no significant improvement in hand dexterity (Table 2). QST showed a decrease in the mechanical detection threshold (became less numb), and for the CIPN patients, the percentage of the distal limb skin which had abnormal sensation in response to brush, cool and warm stimuli decreased and moved distally (Table 3; Fig. 1).

Comparison of responders and non responders at 4-6 weeks

Responders had a significantly greater degree of improvement than nonresponders in catastrophising and dominant hand dexterity but not on other variables (Table 4).

\section{Discussion}

Main finding

This is, to our knowledge, the first clinical study to report an analgesic benefit from the application of topical menthol to treat CIPN and Post-mastectomy Pain Syndrome (PMPS). Eighty-two per cent of evaluable patients had an improvement in their total pain scores after 4-6 weeks of treatment. Fifty per cent had a clinically relevant reduction in pain scores of at least $30 \%$.

Importantly, there were also improvements in objectively measured physical function. The significant increase in walking velocity and cadence are important read-outs of increased

Table 3 Quantitative sensory testing (QST) and proportion of distal limbs with abnormal sensation to brush, cool and warm stimuli at baseline and 4 6 weeks

\begin{tabular}{|c|c|c|c|c|c|}
\hline $\begin{array}{l}\text { Measure } \\
\text { (possible score) }\end{array}$ & Number & $\begin{array}{l}\text { Baseline median } \\
\text { (IQ range) }\end{array}$ & $\begin{array}{l}\text { 4-6 weeks median } \\
\text { (IQ range) }\end{array}$ & $\begin{array}{l}\text { Median of individual } \\
\text { changes }^{\mathrm{a}}(95 \% \mathrm{CI})\end{array}$ & $P$ value \\
\hline \multicolumn{6}{|l|}{ QST } \\
\hline Mechanical detection threshold force ${ }^{\mathrm{c}}(0.026$ to $110 \mathrm{~g})$ & 40 & $1.1(0.3$ to 2.9$)$ & $0.3(0.1$ to 1.1$)$ & $-0.2^{\mathrm{a}}(-7.9$ to 1.7$)$ & $0.016^{\mathrm{b}}$ \\
\hline Mechanical detection threshold NRS ( 0 to 10$)$ & 40 & $0(0.0$ to 0.0$)$ & $0(0.0$ to 0.0$)$ & $0.0^{\mathrm{a}}(-0.3$ to 0.0$)$ & $0.131^{\mathrm{b}}$ \\
\hline Mechanical pain threshold force ${ }^{\mathrm{d}}(0.026$ to $110 \mathrm{~g})$ & 40 & $34(11$ to 110$)$ & $110(17$ to 110$)$ & $0.0^{\mathrm{a}}(-7.4$ to 31.9$)$ & $0.198^{\mathrm{b}}$ \\
\hline Mechanical pain threshold NRS (0 to 10 ) & 39 & $2(0$ to 4$)$ & $1(0$ to 3$)$ & $-0.4(-1.3$ to 0.6$)$ & 0.445 \\
\hline Windup ratio & 40 & $1(0.0$ to 2.0$)$ & $1(0.0$ to 1.3$)$ & $0.0^{\mathrm{a}}(-2.0$ to 0.2$)$ & $0.098^{\mathrm{b}}$ \\
\hline \multicolumn{6}{|l|}{ Extent of abnormal receptive field } \\
\hline \multicolumn{6}{|l|}{ Brush stimulus } \\
\hline$\%$ of forearm below elbow & 20 & 55 (2 to 73$)$ & $24(0$ to 57$)$ & $-16(-32$ to 1$)$ & 0.062 \\
\hline$\%$ of lower leg below knee & 19 & 65 (16 to 82$)$ & 39 (16 to 64$)$ & $-13(-26$ to 0$)$ & 0.056 \\
\hline \multicolumn{6}{|l|}{ Cool $\left(25^{\circ} \mathrm{C}\right)$ stimulus } \\
\hline$\%$ of forearm below elbow & 19 & 70 (34 to 88$)$ & 37 (9 to 79$)$ & $-19(-37$ to -2$)$ & 0.036 \\
\hline$\%$ of lower leg below knee & 19 & 67 (48 to 97$)$ & 43 (21 to 79$)$ & $-24(-36$ to 12$)$ & 0.001 \\
\hline \multicolumn{6}{|l|}{ Warm $\left(40{ }^{\circ} \mathrm{C}\right)$ stimulus } \\
\hline$\%$ of forearm below elbow & 18 & $72(50$ to 88$)$ & 24 (8 to 79$)$ & $-28^{\mathrm{a}}(-39$ to -11$)$ & $0.004^{\mathrm{b}}$ \\
\hline$\%$ of lower leg below knee & 19 & 89 (78 to 93$)$ & $56(20$ to 77$)$ & $-25(-41$ to -10$)$ & 0.003 \\
\hline
\end{tabular}

NRS Numerical Rating Scale (higher scores indicate worse pain), $95 \%$ CI $95 \%$ confidence interval, IQ range interquartile range

${ }^{a}$ Median change (when distribution of variables relating to the change between baseline and 4-6 weeks was not normally distributed)

${ }^{\mathrm{b}}$ Exception — compared using paired $t$ test when Wilcoxon signed rank test used

${ }^{\mathrm{c}}$ Higher values indicate the skin is more numb

${ }^{\mathrm{d}}$ Lower values indicate increased sensitivity to painful stimuli 
Fig. 1 Outline of how abnormal sensation in response to warm stimulus $\left(40{ }^{\circ} \mathrm{C}\right)$ decreased and moved distally after 4-6 weeks of menthol in patients with chemotherapy-induced neuropathy. $* * P<0.01$ by Wilcoxon-matched pairs test baseline

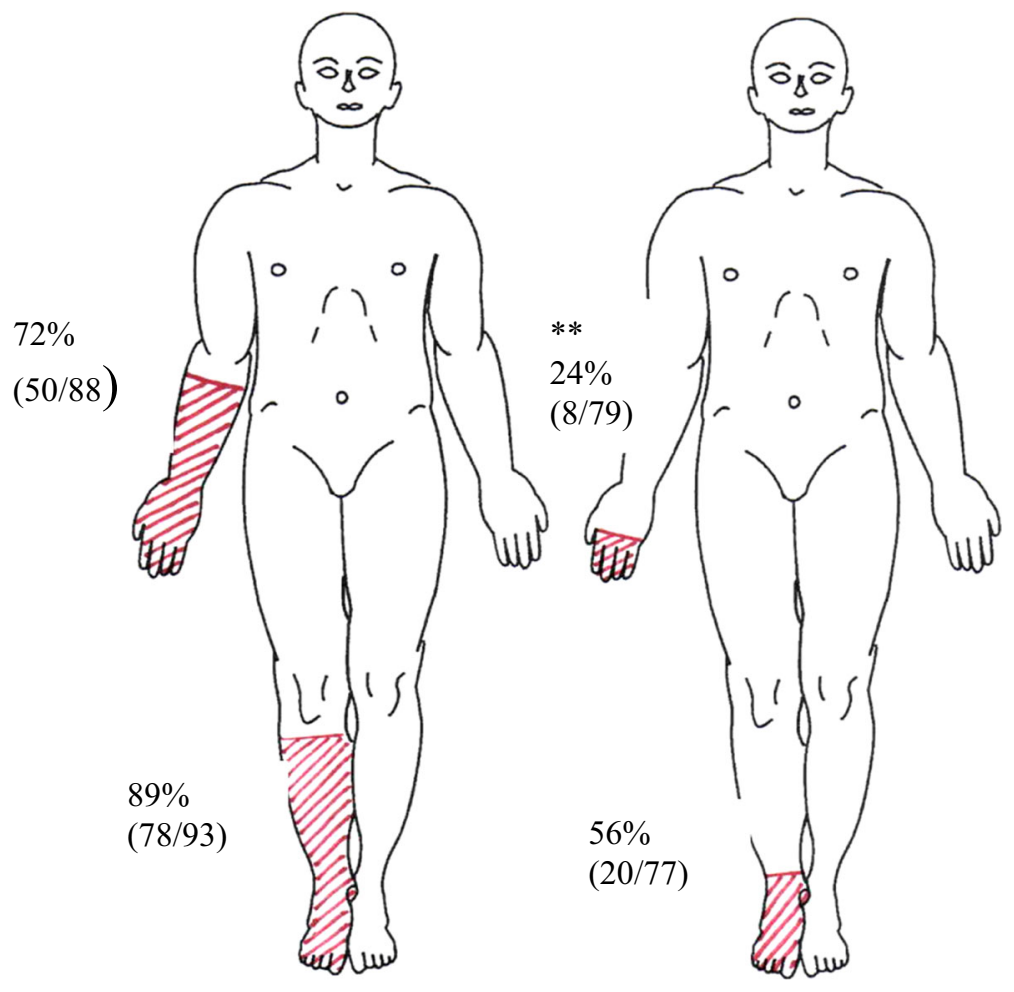

function. Such objective improvements in function increase the likelihood that we are seeing a genuine response to treatment. In addition, QST showed a shrinkage of the skin area with abnormal sensation to several different stimuli (warm, cool and mechanical). The associated changes in mechanical detection threshold and response to warm and cold between baseline and study endpoint again reinforce the evidence for an objective improvement in pain as the key outcome of this study.

\section{Comparison with other studies}

Cooling of injured areas by for example, cold compresses/ icepacks or application of menthol for pain relief has a long history in medicine. The analgesic effect of menthol was reported in 1870 by Wright et al. [36], and its beneficial properties were known to the Ancient Greeks. More recent case reports demonstrated potential increased efficacy for neuropathic pain. While the mechanism of these traditional treatments has long been obscure, our recent demonstration that TRPM8 activation acts through central inhibition of nociceptive input provides a scientific rationale for a new generation of analgesics targeting TRPM8 [22]. In fact, several members of the TRP super family have emerged as important targets for new drugs, especially analgesics, due to their expression in sensory neurons and their critical role in nociception, particularly in chronic pain states [37, 38].

The effective use of menthol depends on the understanding that at higher doses of menthol, there may be off-target effects as it is known to interact with other potentially nociceptive TRP channels and voltage-sensitive channels [39, 40]. Very high concentrations of topically applied menthol (40\%) are overtly noxious and have been used to produce clinical pain models [41], but there are likely to be numerous nonspecific actions at this level.

In this study of topical menthol as an anti-neuropathic agent, the effect was rapid with no dose titration required, which, combined with no apparent side effects, is a clear potential advantage over other neuropathic agents [19].

This work adds significantly to the increasing body of evidence for the efficacy and safety of menthol and peppermint oil as an analgesic in diverse pain states such as muscle strain, migraine, irritable bowel syndrome, post-herpetic neuralgia and CIPN [23, 24, 41-44] and true responders. Despite this, not only did patient show a significant improvement in pain relief, but this was supported by objective clinical biomarker methodology and adherence to the IMMPACT recommendations [25]. 
1. Patients were recruited from one specialist cancer centre and findings may not apply to similar patients treated elsewhere

2. It is possible that some patients may have had a spontaneous improvement in pain and function. However, this is unlikely to have happened in the 6-week study timescale in this patient group, who all had stable, established chronic pain of at least 6 months duration.

The underlying neuropathic pain aetiology varied, however there is accumulating evidence that aetiology is not the driving factor in a treatment response, rather it is the neurobiological changes in any individual, as characterised by QST, which will determine response [45]. These characteristics were examined in detail in this study, using QST. The resolving numbness along with normalisation of response to brush, cold and warm, all moving in synchrony with resolving pain compared with baseline, were important neurosensory biomarkers of response. In this patient sample, it was not possible to identify neurosensory predictors of response: this should be explored in future studies.
It is important when investigating new treatments to examine in detail the characteristics of those who respond versus those who do not respond. Analgesic studies are often dismissed as negative, when in fact there is an important group of responders hidden in the final result. It is accepted that not all patients will respond to a treatment, no matter how promising that treatment. It is crucial however that relevant biomarker data are used to further identify and understand the characteristics of a response. This approach makes identification of responders more scientifically robust and acceptable. In a randomised controlled trial of menthol, both study assessments and a responder analysis will be facilitated by continuing the biomarker work established in this proof of concept study.

\section{Implications for practice}

Chronic established neuropathic pain is particularly difficult to treat and represents a largely unmet therapeutic need. Although progress has been made in curing and prolonging life in patients with cancer, there are a number of long-term

Table 4 Comparison of the mean difference (change) between baseline and 6 weeks for responders and nonresponders (statistically significant $P$ values are set in bold)

\begin{tabular}{|c|c|c|c|c|c|}
\hline \multirow[t]{3}{*}{ 4-6 weeks measure } & \multicolumn{2}{|c|}{ Nonresponder $(n=19)$} & \multicolumn{2}{|c|}{ Responder $(n=19)$} & \multirow[t]{3}{*}{$P$ value $^{\mathrm{a}}$} \\
\hline & \multicolumn{2}{|c|}{ Mean difference (SD) or median (IQ range) } & \multicolumn{2}{|c|}{ Mean difference (SD) or median (IQ range) } & \\
\hline & $n$ & & $n$ & & \\
\hline \multicolumn{6}{|l|}{ Clinical assessments } \\
\hline \multicolumn{6}{|l|}{ HADS } \\
\hline Total & 18 & $-2.1(4.1)$ & 19 & $-3.0(5.7)$ & 0.589 \\
\hline Depression & 18 & $-0.4(2.2)$ & 19 & $-1.1(3.1)$ & 0.459 \\
\hline Anxiety & 18 & $-1.6(2.4)$ & 19 & $-1.8(3.2)$ & 0.807 \\
\hline PCS & 17 & $-1.2(7.5)$ & 19 & $-8.1(5.8)$ & 0.004 \\
\hline LANSS (total) & 19 & $-0.2(4.3)$ & 19 & $-2.4(4.5)$ & 0.129 \\
\hline \multicolumn{6}{|l|}{ Peg board (s) } \\
\hline Dominant hand & 5 & $19(41)$ & 10 & $-25.7(35.4)$ & 0.048 \\
\hline Nondominant hand & 5 & $6.8(39.5)$ & 10 & $-23.6(35.2)$ & 0.153 \\
\hline \multicolumn{6}{|l|}{ GAITRite } \\
\hline Velocity (m/s) & 8 & $8.3(22.9)$ & 12 & $13.8(16.8)$ & 0.536 \\
\hline Cadence (steps/min) & 8 & $2.3(11.9)$ & 12 & $7.8(11.4)$ & 0.310 \\
\hline \multicolumn{6}{|l|}{ QST } \\
\hline Mechanical detection threshold (g) & 19 & $-0.24(-3.4$ to 0.26$)$ & 19 & $-0.26(-0.78$ to 0$)$ & $0.563^{\mathrm{a}}$ \\
\hline Mechanical detection threshold NRS & 19 & $0.0(0.0$ to 0.0$)$ & 19 & $0.0(0.0$ to 0.0$)$ & $0.418^{\mathrm{a}}$ \\
\hline Mechanical pain threshold (g) & 19 & $0.0(-5$ to 17$)$ & 19 & $0.0(-16$ to 86$)$ & $0.863^{\mathrm{a}}$ \\
\hline Mechanical pain threshold NRS & 19 & $-0.2(3.5)$ & 18 & $0.5(2.0)$ & 0.742 \\
\hline Windup ratio & 19 & $0.0(-2.0$ to 0.63$)$ & 19 & $0.0(-2.0$ to 0.5$)$ & $0.729^{\mathrm{a}}$ \\
\hline
\end{tabular}

HADS Hospital Anxiety and Depression scale, LANSS Leeds Assessment of Neuropathic Symptoms and Signs, PCS Pain Catastrophising Scale, NRS Numerial Rating Scale, $95 \%$ CI $95 \%$ confidence interval, IQ range interquartile range

${ }^{\text {a }}$ Exception - all compared using two-sample $t$ test where Mann-Whitney $U$ test used 
treatment-related problems (such as CIPN and PMPS) which can limit further palliative chemotherapeutic options or impact significantly on the patient's quality of life despite being cured of cancer.

The discovery of the TRP channels has provided an opportunity for the development of analgesics, which are potentially more specific for certain pain syndromes and have a better side-effect profile than other interventions. TRP channels are being investigated as novel targets for drug discovery; they have a major advantage over more widely distributed voltagesensitive ion channels, in their potential for achieving analgesia without overwhelming side effects in neuropathic pain [38]. This translational work with topical menthol, a TRPM8 agonist, shows significant promise, and points to the need for further validation through a phase 2 double-blind efficacy study.

If this preliminary work translates into positive further phase $2 / 3$ studies, then it could have a significant impact on quality of life of both many patients being treated for cancer and survivors of cancer.

Acknowledgments CJW was supported in this work by NHS Lothian through the Health Services Research Unit, Edinburgh.

\section{Conflict of interest None}

Open Access This article is distributed under the terms of the Creative Commons Attribution Noncommercial License which permits any noncommercial use, distribution, and reproduction in any medium, provided the original author(s) and the source are credited.

\section{References}

1. Jensen MP, Chodroff MJ, Dworkin RH (2007) The impact of neuropathic pain on health-related quality of life: review and implications. Neurology 68(15):1178-1182

2. Torrance N, Smith BH, Bennett MI et al (2006) The epidemiology of chronic pain of predominantly neuropathic origin. Results from a general population survey. J Pain 7:281-289

3. Doth AH, Hansson PT, Jensen MP et al (2010) The burden of neuropathic pain: a systematic review and meta-analysis of health utilities. Pain 149(2):338-344

4. Toth C, Lander J, Wiebe S (2009) The prevalence and impact of chronic pain with neuropathic pain symptoms in the general population. Pain Med 10(5):918-929

5. Cavaletti G, Alberti P, Frigeni B et al (2011) Chemotherapy-induced neuropathy. Curr Treat Options Neurol 13:180-190

6. Naleschinski D, Baron R, Miaskowski C (2012) Identification and treatment of neuropathic pain in patients with cancer. Pain Clin Updat 20(2):1-5

7. Storey D, Sakala M, McLean C et al (2010) Capecitabine combined with oxaliplatin (CapOx) in clinical practice: how significant is peripheral neuropathy? Ann Oncol 21:1657-1661

8. Argyriou AA, Polychronopoulos P, Iconomou G et al (2008) A review on oxaliplatin-induced peripheral nerve damage. Cancer Treat Rev 34:368-377

9. Vasey PA, Jayson GC, Gordon A et al (2004) Phase III randomized trial of docetaxel-carboplatin versus paclitaxel-carboplatin as first- line chemotherapy for ovarian carcinoma. J Natl Cancer Inst 96: 1682-1691

10. Richardson PG, Briemberg H, Jagannath S et al (2006) Frequency, characteristics, and reversibility of peripheral neuropathy during treatment of advanced multiple myeloma with bortezomib. J Clin Oncol 24:3113-3120

11. Kehlet H, Jensen TS, Woolf CJ (2006) Persistent postsurgical pain: risk factors and prevention. Lancet 367:1618-1625

12. Gärtner R, Jensen M, Nielsen et al (2009) Prevalence of and factors associated with persistent pain following breast cancer surgery. J Am Med Assoc 302(18):1985-1992

13. Sheridan D, Foo I, O'shea H et al (2012) Long term follow up of pain and emotional characteristics of women after surgery for breast cancer. J Pain Symptom Manag 44(4):608-614

14. Haanpaa M, Attal N, Backonja M et al (2011) NeuPSIG guidelines on neuropathic pain assessment. Pain 152:4-27

15. Cruccu G, Sommer C, Anand P et al (2010) EFNS guidelines on neuropathic pain assessment: revised 2009. Eur J Neurol 17:1010 1018

16. Smith BH, Macfarlane GJ, Torrance N (2007) Epidemiology of chronic pain, from the laboratory to the bus stop: time to add understanding of biological mechanisms to the study of risk factors in population-based research? Pain 127:5-10

17. Attal N, Bouhassira D, Baron R et al (2011) Assessing symptom profiles in neuropathic pain clinical trials: can it improve outcome? Eur J Pain 15:441-443

18. Dworkin RH, Turk DC, Katz NP et al (2011) Evidence-based clinical trial design for chronic pain pharmacotherapy: a blueprint for ACTION. Pain 152:S107-S115

19. Selph S, Carson S, Fu R, Thakurta S et al (2011) Drug class review: neuropathic pain. Update 1 final report. Prepared by the Oregon Evidence-based Practice Center for the Drug Effectiveness Review Project. Oregon Health and Science University, Portland

20. Liu Y, Qin N (2011) TRPM8 in health and disease: cold sensing and beyond. Adv Exp Med Biol 704:185-208

21. Eid SR, Cortright DN (2009) Transient receptor potential channels on sensory nerves. Handb Exp Pharmacol 194:261-281

22. Proudfoot CJ, Garry EM, Cottrell DF et al (2006) Analgesia mediated by the TRPM8 cold receptor in chronic neuropathic pain. Curr Biol 16:1591-1605

23. Colvin LA, Johnson PR, Mitchell R et al (2008) From bench to bedside: a case of rapid reversal of bortezomib-induced neuropathic pain by the TRPM8 activator, menthol. J Clin Oncol 26:4519-4520

24. Storey DJ, Colvin LA, MacKean MJ et al (2010) Reversal of doselimiting carboplatin-induced peripheral neuropathy with TRPM8 activator, menthol, enables further effective chemotherapy delivery. J Pain Symptom Manag 39(6):e2-e4

25. Dworkin RH, Turk DC, Peirce-Sandner S et al (2010) Research design considerations for confirmatory chronic pain clinical trials: IMMPACT recommendations. Pain 149:177-193

26. Cleeland CS, Ryan KM (1994) Pain assessment: global use of the Brief Pain Inventory. Ann Acad Med Singap 23:129-138

27. Zigmond AS, Snaith RP, Zigmond AS et al (1983) The hospital anxiety and depression scale. Acta Psychiatr Scand 67:361-370

28. Sullivan M (1995) The Pain Catastrophizing scale: development and validation. Psychol Assess 7:524-532

29. Bennett M (2001) The LANSS pain scale: the leeds assessment of neuropathic symptoms and signs. Pain 92:147-157

30. van Uden CJ, Besser MP (2004) Test-retest reliability of temporal and spatial gait characteristics measured with an instrumented walkway system (GAITRite). BMC Musculoskelet Disord 5:13

31. Ruff RM, Marshall LF, Crouch J et al (1993) Predictors of outcome following severe head trauma: follow-up data from the Traumatic Coma Data Bank. Brain Inj 7:101-111 
32. Schmidt SL, Oliveira RM, Rocha FR et al (2000) Influences of handedness and gender on the grooved pegboard test. Brain Cogn 44:445-454

33. Scott AC, McConnell S, Laird B et al (2002) Quantitative Sensory Testing to assess the sensory characteristics of cancer-induced bone pain after radiotherapy and potential clinical biomarkers of response. Eur J Pain 16:123-133

34. Rolke R, Baron R, Maier C et al (2006) Quantitative sensory testing in the German Research Network on Neuropathic Pain (DFNS): standardized protocol and reference values. [erratum appears in Pain. 2006 Nov;125(1-2):197]. Pain 123:231-243

35. Moore RA, Derry S, McQuay HJ et al (2010) Clinical effectiveness: an approach to clinical trial design more relevant to clinical practice, acknowledging the importance of individual differences. Pain 149: 173-176

36. Wright A (1870) Oil of peppermint as a local anaesthetic. Lancet 2464:726

37. Patapoutian A, Tate S, Woolf CJ (2009) Transient receptor potential channels: targeting pain at the source. Nat Rev Drug Discov 8(1):55-68

38. Moran M, McAlexander MA, Biro T et al (2011) Targeting receptor potential channels as therapeutic targets. Nat Rev Drug Discov 10: $601-620$
39. Karashima Y, Damann N, Prenen J et al (2007) Bimodal action of menthol on the transient receptor potential channel TRPA1. J Neurosci 27(37):9874-9884

40. Gaudioso C, Hao J, Martin-Eauclaire MF et al (2012) Menthol pain relief through cumulative inactivation of voltage-gated sodium channels. Pain 153(2):473-484

41. Wasner G, Schattschneider J, Binder A, Baron R (2004) Topical menthol - a human model for cold pain by activation and sensitization of C nociceptors. Brain 127(Pt 5):1159-1171

42. Higashi Y, Kiuchi T, Furuta K (2010) Efficacy and safety profile of a topical methyl salicylate and menthol patch in adult patients with mild to moderate muscle strain: a randomized, double-blind, parallel-group, placebo-controlled, multicenter study. Clin Ther 32(1):34-43

43. Borhani Haghighi A, Motazedian S, Rezaii R et al (2010) Cutaneous application of menthol $10 \%$ solution as an abortive treatment of migraine without aura: a randomised, double-blind, placebo-controlled, crossed-over study. Int J Clin Pract 64(4):451-456

44. Ford AC, Talley NJ, Spiegel BM et al (2008) Effect of fibre, antispasmodics, and peppermint oil in the treatment of irritable bowel syndrome: systematic review and meta-analysis. BMJ 337:a2313

45. Baron R, Binder A, Wasner G (2010) Neuropathic pain: assessment, understanding and treatment. Lancet Neurol 9:807-819 